\title{
The Role Of High Resolution Ultrasonography To Differentiate Between Benign And Malignant Cervical Lymph Nodes In Oral Squamous Cell Carcinoma
}

\author{
Rahman M A ${ }^{1}$, Sultana N ${ }^{2}$, Uddin M W ${ }^{3}$, Rahman Q B ${ }^{4}$ \\ Received: 18.09.2017 \\ Accepted: 16.11.2017
}

Abstract:

Objectives:The purpose of the study was to evaluate the role of high resolution ultrasonography to differentiate between benign and malignant cervical lymph nodes in oral squamous cell carcinoma. Materials \& Methods:The study was conducted in the Department of Oral and Maxillofacial Surgery, BSMMU,Dhaka, Bangladesh, during a period of January -2010 to December - 2011. A total number of 41 patients with clinical evidence of palpable cervical lymph nodes in oral squamous cell carcinoma were evaluated with high resolution ultrasonography. To evaluate the diagnostic accuracy of high resolutionultrasonography, the high resolution ultrasonography findings were compared and correlated with histopathological examination after neckdissection.

Results: All patients were pre-operatively examined by palpation and high resolution ultrasonography evaluation was done.Among them 41 study subjects, on high resolution ultrasonography evaluation 23(56.09\%) lymph nodes were metastatic and 18(43.90\%) lymph nodes were reactive. After postoperative excisional histopathology examination 22(53.66\%) lymph nodes were metastatic and $19(46.34 \%)$ lymph nodes were reactive in nature. Correlation of vascular flow pattern with histopathological diagnosis showed that central flow for benign nodes, mixed \& peripheral flow for malignant nodes were highly significant parameters $(P<0.001)$. High resolution ultrasonography has specificity $78.94 \%$, sensitivity $86.36 \%$ and diagnostic accuracy of the high resolution ultrasonography was $82.92 \%$.

Conclusion: High resolution ultrasonography can plays a definite role as an adjunct to the clinical evaluation of palpable cervical lymph nodes and proves its value as an important noninvasive investigation procedure for differentiating between benign and malignant cervical lymph nodes in oral squamous cell carcinoma.

Key words: High resolution ultrasonography, palpable cervical lymph nodes, oral squamous cell carcinoma, histopathology

1. Dr. Mohammad Asifur Rahman, Assistant professor, Department of Oral \& Maxillofacial Surgery, Dhaka Dental College Hospital, Dhaka.

2. Dr. Nasreen Sultana, Associate Professor, Institute of Nuclear Medicine and Ultrasound, Bangabandhu Sheikh Mujib Medical University Campus, Dhaka.

3. Dr. Md. Wares Uddin,Associate Professor,Department of Oral \& Maxillofacial Surgery, Bangabandhu Sheikh Mujib Medical University, Dhaka.

4. Dr. QuaziBillurRahman, Professor \& chairman, Department ofOral \& Maxillofacial Surgery,Bangabandhu Sheikh Mujib Medical University, Dhaka.

Correspondence : Dr. Mohammad AsifurRahman, e-mail - asif.omfs@gmail.com, Cell phone - 01712191098 


\section{Introduction}

Squamous cell carcinoma is the most common malignant tumor in the head and neck region. ${ }^{1}$ Approximately $90 \%$ of oral cancers are squamous cell carcinoma. ${ }^{2}$ Assessment and early detection would drastically bring down the morbidity and mortality associated with advanced stages of oral cancer. ${ }^{3}$ In the treatment of patients with oral squamous cell carcinoma of the oral cavity size of primary lesion, site, thickness, histological staging and presence or absence of metastatic spread are important to formulate a treatment plan. ${ }^{4}$

Lymphatic spread is the most important mechanism in the spread of the head and neck squamous cell carcinomas. ${ }^{5}$ The presence or absence of lymph node metastasis has a great impact on the prognosis and survival of patients with oral cancer. Nodal metastasis to one side decreases the survival rate by $50 \%$, while bilateral metastasis decreases survival by a further $25 \% .4,6,7,8$ The neck status is the single most important indicator of prognosis in head and neck cancers. $^{9}$

Management of the lymph node in neck region in patients with oral squamous cell carcinoma is controversial. Some surgeon's advice elective treatment of the neck while others do not support that. ${ }^{4}$ It is possible to reduce the risk of undiagnosed metastasis with accurate imaging techniques and thus probably reduce the number of elective neck treatments. ${ }^{10}$ Several imaging modalities have been used in evaluating the status of cervical lymph nodes in oral squamous cell carcinoma. Ultrasonography, ultrasound-guided fine needle aspiration cytology (FNAC), Computed Tomography (CT), Magnetic Resonance Imaging (MRI), Positron Emission Tomography (PET) and Lymphoscintigraphy. The continuous advanced techniques lead to an increasing sensitivity of the imaging modalities in the detection of lymph nodes. However, differentiationbetween benign and malignant lymph nodes is not possible as far as conventional ultrasound examination, CT and MRI are concerned. ${ }^{11,12,13}$ Though ultrasound - guided fine needle aspiration cytology (FNAC) has a higher diagnostic accuracy ${ }^{11,14}$ but puncturing the metastatic lymph node with the risk of micro dissemination of cancer cells, rupturing the capsule of the metastatic node and infectionmay occurs following the FNAC procedure. ${ }^{15}$

High-resolution ultrasonography has been commonly used to evaluate cervical lymphadenopathy and the role of gray-scale ultrasonography in the assessment of cervical lymph nodes is well established. ${ }^{16,17,18}$
Gray-scale ultrasonography is widely used to assess cervical nodes for their number, site, size, nodal boundary, hilum, adjacent soft tissue edema and other internal nodal echo patterns. ${ }^{16,17}$ But gray-scale ultrasonography is not sensitive enough in differentiation of malignant and benign lymph nodes. ${ }^{13,19}$ The application fields of color Doppler and power Doppler ultrasonography are broad and Doppler ultrasonography was suggested to be used for differentiation of benign and malignant lymph nodes.

Color Doppler ultrasonography is a medical imaging technique which is used to provide visualization of the blood flow, using color processing to add color to the image so that we can clearly see what is happening inside the body. Color Doppler ultrasonography is a non-invasive investigation procedure that can define the morphological and vascular characteristics of lymph nodes. The presence of intra nodal vascularity, its distribution and estimates of the intravascular resistance and spectral Doppler analysis are evaluated with color Doppler. ${ }^{14}$ All these intra nodal vascular alterations helps in differentiating benign from malignant lymph nodes. ${ }^{20,21}$ With the development of technology and the introduction of power Doppler ultrasonography, assessment of the vascularity of lymph nodes by ultrasound has become more accurate. ${ }^{21,22,23}$ In comparison with color Doppler ultrasonography, power Doppler ultrasonography is more sensitive in detection of structures with low volume of fluid 24,25 and it is more accurate in the assessment of small vessels, those found in lymph nodes. ${ }^{26}$

In this article we evaluated the role of high resolution ultrasonography characteristics of cervical lymph nodes in patients with oral squamous cell carcinoma to determine a more reliable method of distinguishing benign from malignant lymph nodes in oral squamous cell carcinoma.

\section{Aims \& Objectives}

1. To evaluate the role of high resolution ultrasonography to differentiate between benign and malignant cervical lymph nodes in oral squamous cell carcinoma.

2. To evaluate the Doppler recorded blood flow patterns increases the diagnostic accuracy of detecting metastatic lymph nodes.

3. To assess the reactive and metastatic features of cervical lymph nodes in oral squamous cell carcinoma by high resolutionultrasonography.

4. To correlate between the ultrasonography findings and histopathology findings of palpable cervical lymph nodes in oral squamous cell carcinoma. 


\section{Materials \& Methods}

A prospective cross sectional observational study was designed.

Study population: The study was performed in Department of Oral and Maxillofacial Surgery, Faculty of Dentistry, BSMMU, Dhaka, Bangladesh from January - 2010 to December - 2011, where a significant number of oral squamous cell carcinoma patients were admitted regularly. Among them 41 study subjects were selected, who fulfilled the inclusion criteria. Inclusion Criteria: I) All admitted patients diagnosed histopathologically as squamous cell carcinoma in oral cavity. II) Patients of oral squamous cell carcinoma with clinical evidence of palpable cervical lymph nodes. Exclusion Criteria: I) Patients of oral squamous cell carcinoma was declared as inoperable for the primary tumor. II) Inoperable for advanced neck metastasis. III) Inoperable for systemic diseases. IV) Patients who received previous radiotherapy.

Study Procedure: Diagnosis was made by accurate history, clinical examination, histopathological examination from the primary lesion andhigh resolution ultrasonography examination. After obtained an informed written consent all patients were evaluated with high resolution ultrasonography by an experienced radiologist.

The high resolution ultrasonography study was conducted with Siemens Acouson Antares equipped with broadband (frequency bands $5-10 \mathrm{MHz}$ ) linear array transducer. The Doppler parameter was adjusted for low velocity or low volume flow or both. PRF $800 \mathrm{kHz}$, Band pass filter was $62 / 75 \mathrm{~Hz}$.

The patient should be supine in positioned with the neck hyper-extended. A pillow should be placed under the shoulders for support the lower neck region. The patient was remained in this position for 5 minutes before the examination was started to ensure the blood flow was measured at rest in position.

The examination was started with a transverse scan of the sub mental area. The transducer was then swept laterally to one side of the neck while the patient's headrotates towards the opposite side to allow free manipulation of the transducer. The submandibular region was examined with a transverse scan along the inferior border of the mandibular body. The internal jugular chain nodes were examined in transverse scan along the internal jugular vein and common carotid artery from the tail of parotid gland to the junction between internal jugular vein and the subclavian vein. The posterior triangle nodes were examined. The same scanning protocol was used on the opposite side of the neck so that the major nodal chain in the neck was covered.

All cervical lymph nodes in each region were assessed for size, shape, echogenic hilum and vascularity. The vascular pattern of each cervical lymph node was determined and classified according to the location of the vascularity. (1) Central (hilar) flow with a single vascular signal branching radially from the center, originating symmetrically and showing a regular course from the lymph nodal hilum (2) Peripheral (capsular) flow signals along the periphery of the lymph nodes, with branches perforating the periphery of the lymph node and not arising from the hilar vessels (3) Mixed the presence of central and peripheral vascular flow patterns (4) Absent or no vascular signals within the lymph nodes. The blood flow pattern and vascular resistance (Resistive index and Pulsatility index) were measured and recorded. Histopathological diagnosis was performed after neck dissection that was done by the Oral and Maxillofacial surgeon and after that each cervical lymph node was histopathologically determined to be metastatic or reactive. Then a correlation was done between the high resolution ultrasonography findings and histopathological findings of palpable cervical lymph nodes in oral squamous cell carcinoma.

\section{Data Processing and Analysis}

Data were processed and analyzed by using computer software SPSS version 19 for windows. Level of significance was set at 0.05 and $p$ value $<0.05$ was considered significant.

\section{Results}

The study was performed in Department of Oral and Maxillofacial Surgery, Faculty of Dentistry, BSMMU, Dhaka, Bangladesh from January-2010 to December-2011, where a significant number of oral squamous cell carcinoma patients were admitted regularly. Among them 41 study subjects, on high resolution ultrasonography evaluation $23(56.09 \%)$ lymph nodes were metastatic $18(43.90 \%)$ lymph nodes were reactive. After postoperative excisional histopathology examination $22(53.66 \%)$ lymph nodes were metastatic and $19(46.34 \%)$ lymph nodes were reactive in nature. 
Table 1: Distribution of the study subjects by age.

\begin{tabular}{|l|l|l|}
\hline Age group & Frequency & Percentage $(\%)$ \\
\hline $30-40$ years & 12 & 29.3 \\
\hline $41-50$ years & 10 & 24.39 \\
\hline $51-60$ years & 11 & 26.8 \\
\hline$>60$ years & 08 & 19.51 \\
\hline Total & 41 & 100.0 \\
\hline Mean $( \pm$ SD $)$ & $51.70( \pm 11.11)$ & Range $35-70$ \\
\hline
\end{tabular}

The table shows the age distribution of the study subjects. Out of 41 subjects 12 (29.3\%) were between $30-40$ years, 10 (24.39\%) were $41-50$ years, $11(26.8 \%)$ were $51-60$ years and $08(19.51 \%)$ were above 60 years. The age of the study subjects ranged from $35-70$ years Mean age $(+/-S D)=51.70(\nabla$ 11.11) years.

Figure 1: Distribution of study subjects by their habits.

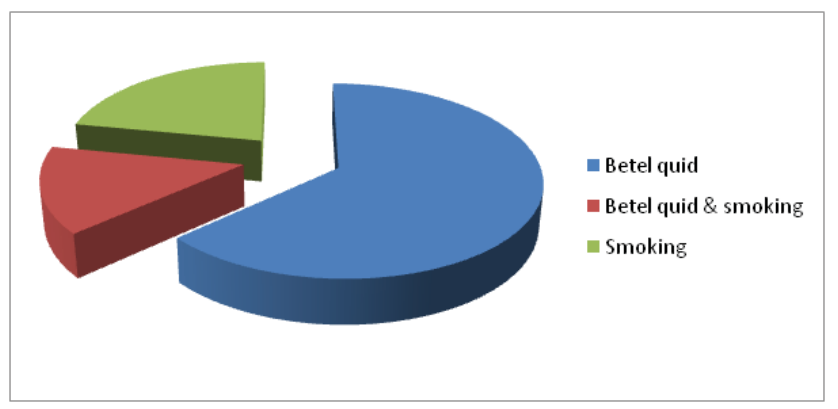

This pie diagram shows distribution of study subjects by their habits. Among them 26 (63.4\%) were habituated to betel quid chewing, $06(14.6 \%)$ were habituated both betel quid and smoking, 09 (22.0\%) were smoking respectively.

Table 2: Evaluation of cervical lymph nodes in the study subjects.

\begin{tabular}{|l|l|l|l|}
\hline Evaluation of lymph nodes & \multicolumn{1}{|c|}{ Metastatic } & Reactive & Total \\
\hline Clinical evaluation & $25(60.98 \%)$ & $16(39.02 \%)$ & $41(100.0 \%)$ \\
\hline Ultrasonography evaluation & $23(56.09 \%)$ & $18(43.90 \%)$ & $41(100.0 \%)$ \\
\hline Excisional Histopathology & $22(53.66 \%)$ & $19(46.34 \%)$ & $41(100.0 \%)$ \\
\hline
\end{tabular}

Table 3: Distribution of vascular flow pattern in cervical lymph nodes by Doppler ultrasonography.

\begin{tabular}{|l|l|l|l|l|}
\hline \multirow{2}{*}{ Vascular flow pattern } & \multicolumn{2}{|l|}{ Excisional Histopathology } & \multirow{2}{*}{ Total } & \multirow{2}{*}{ P value } \\
\cline { 2 - 3 } & Metastasis & Reactive & 23(56.10\%) & \\
\hline $\begin{array}{l}\text { Peripheral \& mixed flow } \\
\text { pattern }\end{array}$ & $19(86.37 \%)$ & $04(21.05 \%)$ & & $<0.001^{\mathrm{s}}$ \\
\hline Centralflow pattern & $03(13.63 \%)$ & $15(78.95 \%)$ & $18(43.90 \%)$ & \\
\hline Total & $22(100 \%)$ & $19(100 \%)$ & $41(100 \%)$ & \\
\hline
\end{tabular}

The table shows vascular flow pattern in cervical lymph nodes. Among 22 metastatic nodes, 19 $(86.37 \%)$ metastatic nodes had a mixed and peripheral pattern of blood flow and $03(13.63 \%)$ metastatic nodes had a central pattern of blood flow within the lymph nodes. Among 19 reactive nodes, 04 (21.05\%) reactive nodes had a mixed and peripheral pattern of blood flow and $15(78.95 \%)$ reactive nodes had a central pattern of blood flow. Significant differences were found in different outcome of vascular flow pattern $(p<0.05)$ in chi- square test.

Table 4: Distribution of Resistive index (RI) in cervical lymph nodes by Doppler ultrasonography.

\begin{tabular}{|l|l|l|l|l|}
\hline $\begin{array}{l}\text { Resistiv } \\
\text { e index }\end{array}$ & \multicolumn{2}{|c|}{ Excisional Histopathology } & & \\
\cline { 2 - 5 } & Metastatic & Reactive & Total & P value \\
\hline RI $>0.6$ & $20(90.9 \%)$ & $07(36.84 \%)$ & $27(65.85 \%)$ & \\
\hline RI $\leq 0.6$ & $02(9.10 \%)$ & $12(63.16 \%)$ & $14(34.15 \%)$ & $0.001^{\mathrm{s}}$ \\
\hline Total & $22(100.0 \%)$ & $19(100.0 \%)$ & $41(100.0 \%)$ & \\
\hline
\end{tabular}

The table shows the resistive index (RI) in cervical lymph nodes. Among the 22 metastatic nodes R.I. $>0.6$ was observed in $20(90.9 \%)$ metastatic nodes and R.I. $<0.6$ was observed in $02(9.10 \%)$ metastatic nodes. Among the 19 reactive nodes R.I. $>0.6$ was observed in $07(36.84 \%)$ reactive nodes and R.I. $<0.6$ was observed in 12(63.16\%) reactive. Significant differences were found in different outcome of $\mathrm{RI}(\mathrm{p}<$ 0.05 ) in chi- square test.

Table 5: Distribution of Pulsatility index (PI) in cervical lymph nodesby Doppler ultrasonography.

\begin{tabular}{|l|l|l|l|l|}
\hline \multirow{2}{*}{$\begin{array}{l}\text { Pulsatilit } \\
\text { y index }\end{array}$} & \multicolumn{2}{|l|}{ Excisional Histopathology } & & \\
\cline { 2 - 5 } & Metastatic & Reactive & Total & P value \\
\hline PI $>1.1$ & $21(95.45 \%)$ & $07(36.84 \%)$ & $28(68.30 \%)$ & \multirow{2}{*}{ s.001 } \\
\hline PI < 1.1 & $01(04.55 \%)$ & $12(63.16 \%)$ & $13(31.70 \%)$ & \\
\hline Total & $22(100 \%)$ & $19(100 \%)$ & $41(100 \%)$ & \\
\hline
\end{tabular}

The table shows the pulsatility index (PI) in cervical lymph nodes. Among the 22 metastatic nodes P.I $>1.1$ was observed in $21(95.45 \%)$ metastatic nodes and P.I. $<1.1$ was observed in 01(04.55\%) metastatic nodes. Among the 19 reactive nodes P.I.>1.1 was observed in $07(36.84 \%)$ reactive nodes and P.I. < 1.1.was observed in $12(63.16 \%)$ reactive nodes. Significant differences were found in $(p<0.05)$ chisquare test.

Table 6: Diagnostic accuracy of vascular pattern, Resistive index, Pulsatility index. 


\begin{tabular}{|c|c|c|c|c|c|}
\hline $\begin{array}{l}\text { Diagnostic } \\
\text { Accuracy }\end{array}$ & Sensitivity & Specificity & PPV & NPV & $\begin{array}{l}\text { Accurac } \\
\mathrm{y}\end{array}$ \\
\hline $\begin{array}{l}\text { Vascular } \\
\text { pattern }\end{array}$ & $86.36 \%$ & $78.94 \%$ & $86.36 \%$ & $83.33 \%$ & $82.92 \%$ \\
\hline $\begin{array}{l}\text { Resistive } \\
\text { index ( RI ) }\end{array}$ & $90.91 \%$ & $63.16 \%$ & $74.07 \%$ & $85.71 \%$ & $78.04 \%$ \\
\hline $\begin{array}{l}\text { Pulsatility } \\
\text { index ( PI ) }\end{array}$ & $95.45 \%$ & $63.16 \%$ & $75.0 \%$ & $92.31 \%$ & $80.48 \%$ \\
\hline
\end{tabular}

The above table shows the diagnostic accuracy of vascular pattern, RI and PI. Sensitivity of vascular pattern were $86.36 \%$ Specificity $78.94 \%$ predictive value for a positive test $86.36 \%$ and predictive value for a negative test $83.33 \%$ respectively. Sensitivity of resistive index (RI) were $90.91 \%$, Specificity $63.16 \%$, predictive value for a positive test and predictive value for a negative test were found $74.07 \%$ and $85.71 \%$ respectively. Sensitivity of pulsatility index (PI) were $95.45 \%$, Specificity $63.16 \%$, predictive value for a positive test and predictive value for a negative test were found $75.0 \%$ and $92.31 \%$ respectively. In the analysis the accuracy of vascular pattern, RI and PI of color Doppler ultrasonography were, $82.92 \%, 78.04 \%, 80.48 \%$ respectively.

Table7: Correlation of high resolution ultrasonography evaluation with histopathology examination.

\begin{tabular}{|l|l|l|l|l|}
\hline \multirow{2}{*}{$\begin{array}{l}\text { High resolution } \\
\text { ultrasonography } \\
\text { evaluation }\end{array}$} & \multicolumn{2}{|l|}{ Excisional Histopathology } & \multirow{2}{*}{ Total } & \multirow{2}{*}{ P value } \\
\cline { 2 - 4 } & Metastasis & Reactive & & \\
\hline Metastasis & $19(86.37 \%)$ & $04(21.05 \%)$ & $23(56.10 \%)$ & \\
\hline Reactive & $03(13.63 \%)$ & $15(78.95 \%)$ & $18(43.90 \%)$ & $0.001^{\mathrm{s}}$ \\
\hline Total & $22(100 \%)$ & $19(100 \%)$ & $41(100 \%)$ & \\
\hline
\end{tabular}

The above table shows the diagnostic accuracy of vascular pattern, RI and PI. Sensitivity of vascular pattern were $86.36 \%$ Specificity $78.94 \%$ predictive value for a positive test $86.36 \%$ and predictive value for a negative test $83.33 \%$ respectively. Sensitivity of resistive index (RI) were $90.91 \%$, Specificity $63.16 \%$, predictive value for a positive test and predictive value for a negative test were found $74.07 \%$ and $85.71 \%$ respectively. Sensitivity of pulsatility index (PI) were $95.45 \%$, Specificity $63.16 \%$, predictive value for a positive test and predictive value for a negative test were found $75.0 \%$ and $92.31 \%$ respectively. In the analysis the accuracy of vascular pattern, RI and PI of color Doppler ultrasonography were, $82.92 \%, 78.04 \%, 80.48 \%$ respectively.

Table7: Correlation of high resolution ultrasonogra- phy evaluation with histopathology examination.

\begin{tabular}{|c|c|c|c|c|c|}
\hline Diagnostic Accuracy & Sensitivity & Specificity & PPV & NPV & Accuracy \\
\hline $\begin{array}{l}\text { High-resolution } \\
\text { ultrasonography }\end{array}$ & $86.36 \%$ & $78.94 \%$ & $\begin{array}{l}86.36 \\
\%\end{array}$ & $\begin{array}{l}83.33 \\
\%\end{array}$ & $82.92 \%$ \\
\hline
\end{tabular}

The above table shows the diagnostic accuracy of high resolution ultrasonography. Sensitivity of high resolution ultrasonography were $86.36 \%$, Specificity $78.94 \%$, predictive value for a positive test $86.36 \%$, and predictive value for a negative test $83.33 \%$ were found and respectively. In the analysis the accuracy of color Doppler ultrasonography were $82.92 \%$ respectively.

\section{Discussion}

High-resolution ultrasonography is preferred over other imaging methods in determination of lymph nodes and in pursuit of the disease. ${ }^{27,28}$

The role ofhigh resolution Doppler ultrasound in the evaluation of metastatic lymph nodes is based on the fact that tumors larger than a few millimeters in diameter stimulate the growth of new vessels. This tumor neo - vascularity has certain characteristics that enable a presumptive diagnosis of malignancy to be made.29 In evaluating nodal vascularity, Doppler ultrasound assesses two main feature. ${ }^{14,21,26,27,30,31}$

1. Distribution of vessels within the lymph node.

2. Vascular parameters detecting intravascular resistance (RI, PI).

The vascular pattern of the enlarged lymph nodes was classified into the following four groups according to the location of the vascularity (1) Central flow signals branching radially from the center (2) Peripheral flow signals along the periphery of the lymph nodes, with branches perforating the periphery of the node and not arising from the hilar vessels (3) Mixed the presence of central and peripheral flow signals (4) No flow or apparent avascular, absence of vascular signals within the lymph nodes. ${ }^{30}$ (Fig:1, 2, 3)

Normal and reactive lymph nodes tend to show hilar vascularity / central vascularity. ${ }^{23,27,31}$ Peripheral or mixed nodal vascularity are common in metastatic nodes. The peripheral vascularity in metastatic nodes is believed to be related to tumor infiltration of the lymph nodes in which the tumor cells produce tumor angiogenesis factor (TAF) which causes angiogenesis and recruitment of peripheral vessels. ${ }^{21,22,23}$ Mixed flow of the metastatic node was explained by two pathogeneses. First, as the tumor nests replace the lymph node, the pre-existing nodal vessels may be 
proliferated and transformed into feeding vessels by tumor angiogenesis, resulting in central aberrant nodal vessels. Second, advanced tumor infiltration of a lymph node will destroy the hilar blood supply, resulting in induction of the vascular supply from the peripheral pre-existing vessels in perinodal connective tissue, which may be accelerated by extra capsular invasion. ${ }^{21}$

Many studies stated that, absence of perfusion in a lymph node is an important feature suggesting its malignant nature because total replacement of the whole lymph node by necrosed and keratinized tumors tissue. ${ }^{15,22}$

In our study the distribution of vascular flow pattern in cervical lymph nodes shows in excellent result. Among 22 metastatic nodes, 19(86.37\%) metastatic nodes had a mixed and peripheral pattern of blood flow and $03(13.63 \%)$ metastatic nodes had a central pattern of blood flow within the lymph nodes. Among 19 reactive nodes, 04(21.05\%) reactive nodes had a mixed and peripheral pattern of blood flow and $15(78.95 \%)$ reactive nodes had a central pattern of blood flow statistically highly significant in this study. The vascular resistance in terms of resistive index $(\mathrm{RI})$ and pulsatility index (PI) can be evaluated with the use of color Doppler ultrasonography.(Fig: 4, 5, 6) We know, metastatic lymph nodes involved in a pattern by which metastatic tumors enter the lymph nodes through the afferent lymphatic vessels and colonize the marginal sinuses and then enter the medulla and the hilum in the end. ${ }^{32}$ As tumor cells spread into the lymph nodes, they grow and replace a large portion of the lymph node and at last the lymph node is totally replaced by tumor cells. At this stage tumor cells compress vessels in the lymph node because a limited space is there. This vascular compression by tumor cells increases vascular resistance, causing an increase in the RI. ${ }^{14}$ The vascular resistance of metastatic nodes is higher than that of reactive nodes. ${ }^{21,23,31,33}$ However some studies suggested that the vessels in a metastatic lymph node had lower vascular resistance due to the absence of a muscle layer in tumor vessels and the presence of arteriovenous shunting. ${ }^{14,33,34}$

Different cut-off values of $\mathrm{RI}(0.6,0.7$ and 0.8$)$ and PI $(1.1,1.5$ and 1.6) in differentiating metastatic and reactive lymph nodes have been reported. ${ }^{21,22,23,34}$ In this study, we applied the cut-off points (RI 0.6 and PI 1.1) and observed that among the 22 metastatic nodes R.I. > 0.6 was observed in 20(90.9\%) metastatic nodes and R.I. $<0.6$ was observed in $02(9.10 \%)$ metastatic nodes. Among the 19 reactive nodes R.I. > 0.6 was observed in $07(36.84 \%)$ reactive nodes and R.I. < 0.6 was observed in 12(63.16\%) reactive nodes. Among the 22 metastatic nodes P.I > 1.1 was observed in $21(95.45 \%)$ metastatic nodes and P.I. $<1.1$ was observed in $01(04.55 \%)$ metastatic nodes. Among the 19 reactive nodes P.I.>1.1 was observed in $07(36.84 \%)$ reactive nodes and P.I. < 1.1.was observed in $12(63.16 \%)$ reactive nodes.

The analysis of patterns of nodal vascularity along with R.I. and P.I can be used to differentiate benign from malignant cervical lymph nodes in oral squamous cell carcinoma with high sensitivity and high specificity. On the basis of the presence of color flow pattern, the sensitivity and specificity in this study were $(86.36 \%)$ and $(78.94 \%)$ respectively, which were nearly similar to Dangoreet al. ${ }^{29}(87.60 \%)$ and $(91.66 \%)$ respectively. Overall results of color Doppler flow criteria were statistically highly significant in this study $(P<0.01)$.

In this study we found that sensitivity $(90.91 \%)$, specificity $(63.16 \%)$ and accuracy $(78.04 \%)$ for RI and sensitivity (95.45\%), specificity $(63.16 \%)$ and accuracy $(80.48 \%)$ for PI. Dangoreet al. ${ }^{29}$ applied the cut-off points (RI 0.7 and $\mathrm{PI} 1.5$ for malignant nodes) and found that the sensitivity (64\%) and specificity $(81.18 \%)$ respectively. The results of our study showed that there was a statistically significant which was comparable with previous studies by Steinkampet al. ${ }^{22}$

In this study the sensitivity, specificity and accuracy of the high resolution ultrasonography was sensitivity (86.36\%) specificity (78.94\%) and accuracy (82.92\%) which is comparable to Dangoreet al. ${ }^{29}$ where accuracy was (92.85\%) and specificity was (94.28\%). Haberal (2004) et al. ${ }^{8}$ found (85\%) accuracy with sensitivity $(72 \%)$ specificity $(96 \%)$. Sadat et al. ${ }^{35}$ found $(72.4 \%)$ accuracy with sensitivity (93.33\%) specificity $(50 \%)$.

Giovagnorioet al. ${ }^{12}$ reported thatcolor Doppler ultrasound is promising because it is easily applicable and does not require calculations. Some study stated that tissue characterization is not possible by ultrasound and it cannot detect early-stage of malignant lymphadenopathy. ${ }^{21}$ The use of high-frequency transducers has improved the ability to detect and interrogate the vascular signals.Dragoniet al. ${ }^{31}$ investigated superficial lymph node enlargement in 71 patients undergoing surgical biopsy at the onset of lymphadenopathy with high resolution pulsed and color Doppler ultrasonography. They observed volume, vascularization score, pulsatility index, and resistive index were significantly higher in their study. They 
concluded that high resolution pulsed and color Doppler ultrasound may provide information that is useful in making correct differential diagnoses of malignant or benign lymphadenopathy.

The combined use of high resolution ultrasonography with Doppler spectral waveform analysis by means of color Doppler and power Doppler ultrasonography will improve the diagnostic accuracy in differentiating benign from malignant lymph nodes in oral squamous cell carcinoma.

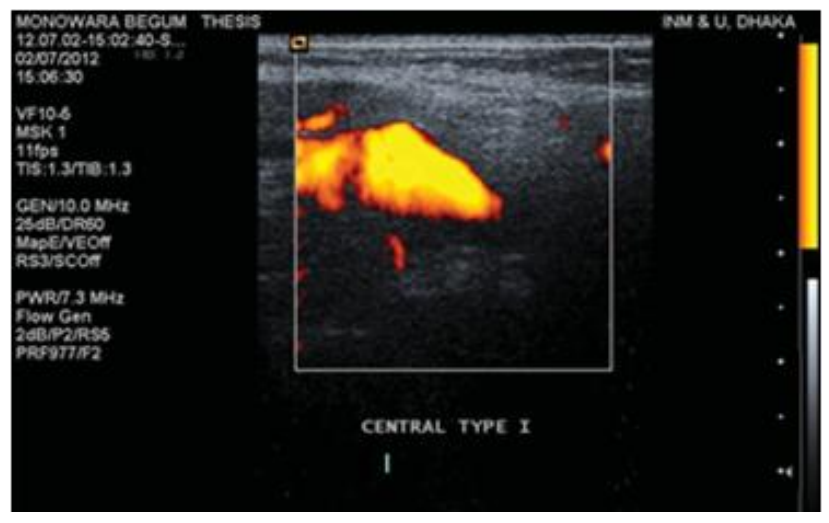

Fig: 1. Doppler ultrasonogram analysis of a lymph node with central pattern of vascular flow.

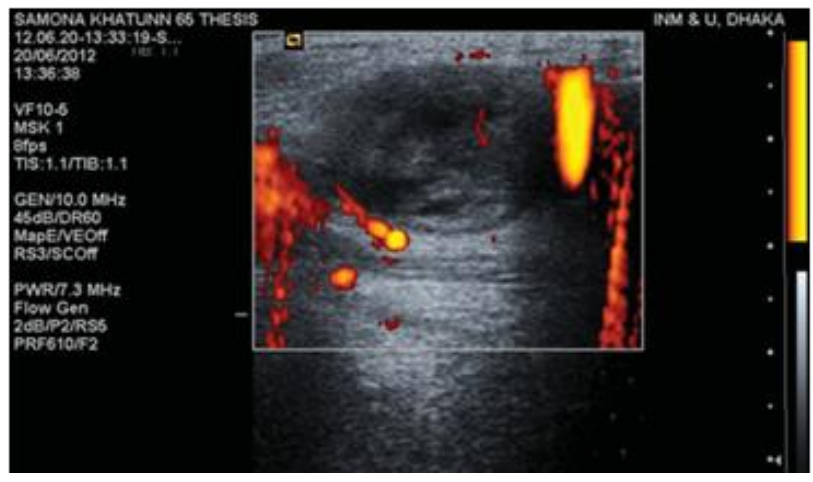

Fig: 2. Doppler ultra sonogram analysis of a lymph node with peripheral pattern of vascular flow.

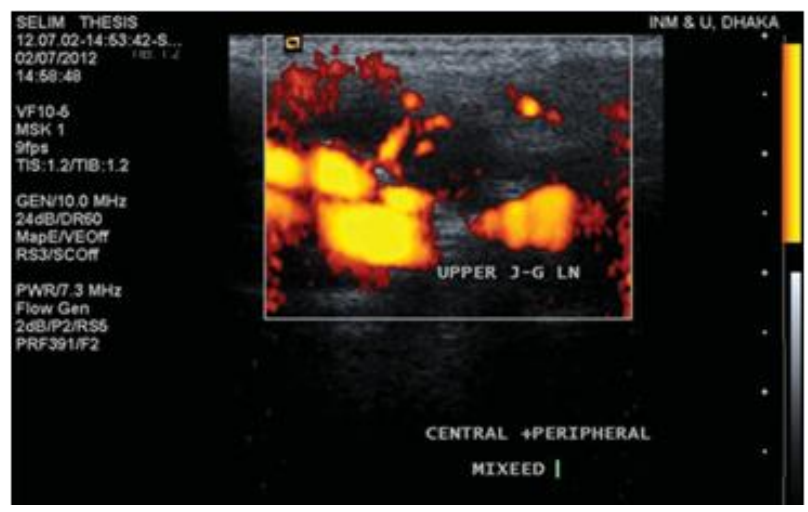

Fig: 3. Doppler ultrasonogram analysis of a lymph node with mixed pattern of vascular flow.

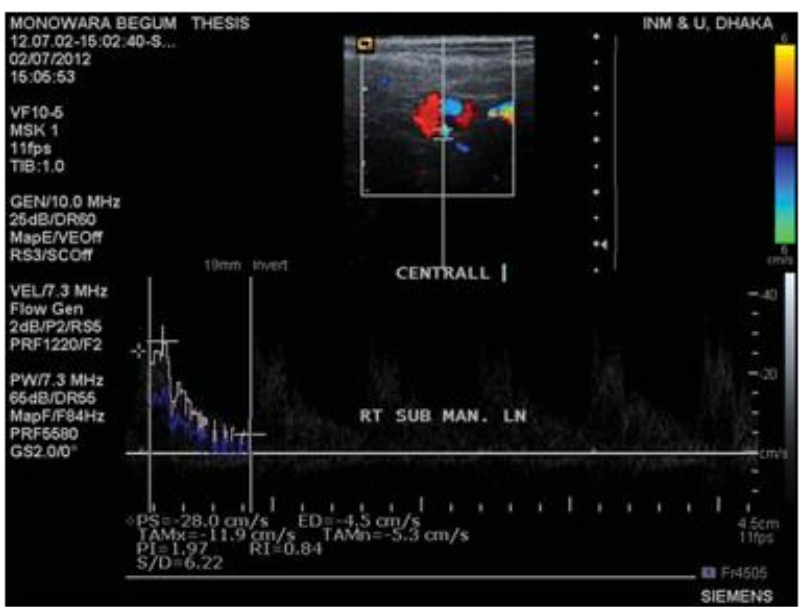

Fig: 4. Doppler ultra sonogram with spectral wave form analysis with central pattern of vascular flow

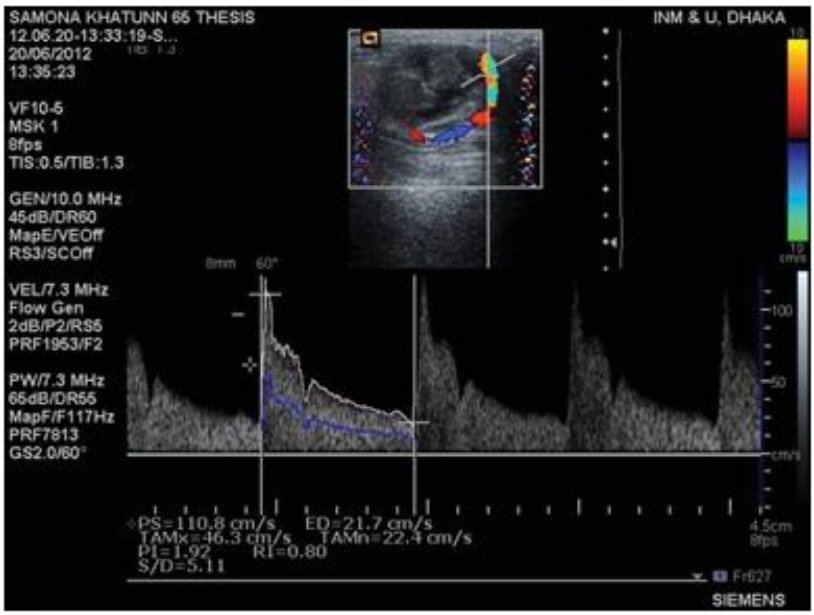

Fig: 5. Doppler ultra sonogram with spectral wave form analysis with peripheral pattern of vascular flow

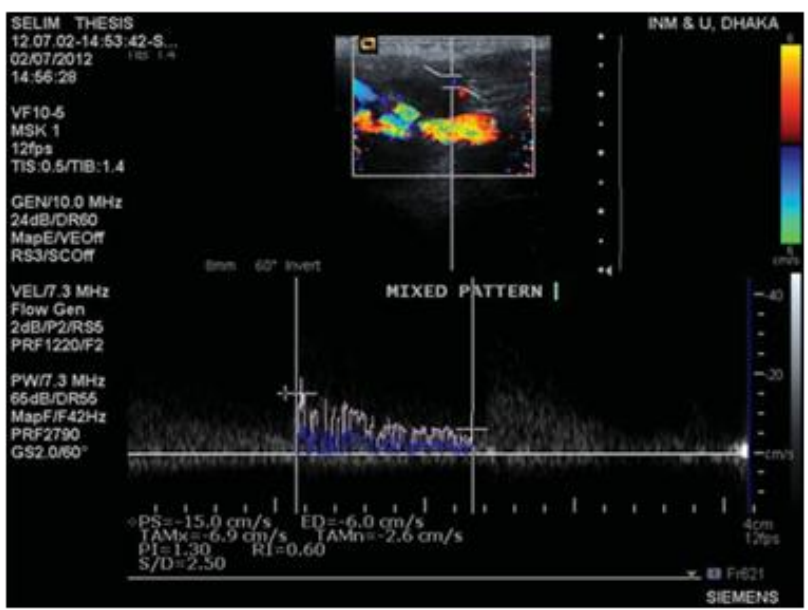

Fig: 6. Doppler ultra sonogram with spectral wave form analysis with mixed pattern of vascular flow. 


\section{Conclusion}

High resolution ultrasonography with Doppler spectral waveform analysis by means of color Doppler and power Doppler ultrasonography plays a definite role as an adjunct to the clinical evaluation of cervical lymphadenopathy and proves its value as an important noninvasive investigation procedure for differentiating between benign and malignant cervical lymph nodes in oral squamous cell carcinoma and its high diagnostic accuracy can improve the performance for the diagnosis of palpable cervical lymph nodes in oral squamous cell carcinoma and we recommend it in regular clinical practice.

\section{References}

1. Rothenberg SM, Ellisen LW. The molecular pathogenesis of head and neck squamous cell carcinoma. J Clin Invest. 2012; 122: 1951-1957.

2. Campbell WJ, Torre JIDL, Head and Neck Cancer. Squamous cell carcinoma Division of plastic surgery, University of Alabama at Birmingham. 2008; web http: / emedicine.mediscape.com

3. Kansara A, Sharma S.M.Evaluation of Cervical lymph node Metastasis in Oral Squamous Cell Carcinoma: Comparison between Palpation, USG, CT Scan \& Histopathology.(IOSR-JDMS). 2016; Vol. 15, PP 49-54

4. Hodder SC, Evans RM, Patton DW, Silvester KC. Ultrasound and fine needle aspiration cytology in the staging of neck lymph nodes in oral squamous cell carcinoma. British Journal of Oral and Maxillofacial Surgery.2000; 38:430-436.

5. Mokhtari S. Mechanisms of cyst formation in metastatic lymph nodes of head and neck squamous cell carcinoma. DiagnPathol. 2012; 7: 6.

6. Saravanan K, Bapuraj R, Sharma SC, Radotra BD, Khandelwal N, Suri S. Computed tomography and ultrasonographic evaluation of metastatic cervical lymph nodes with surgico-clinicopathologiccorrelation. The Journal of Laryngology and Otology. March 2002; 116: 194 $-199$.

7. D'Souza O, Hasan S, Chary G, Hoisala VR, Carrea M. Cervical lymph node metastases in head and neck malignancy-A clinical / ultrasonographic / histopathological comparative study. The Indian Journal of Otolaryngology: Head and Neck Surgery. 2003; 55:90-93.

8. Haberal I, Celik H, Gocmen H, Akmansu H, Yoruk M, Ozeri C. Which is important in the evaluation of metastatic lympn nodes in head and neck cancer: Palpation,
Ultrasonography or computed tomography? Otolaryngol Head Neck Surg. 2004; 130: 197-201.

9. Som PM. Detection of metastasis in cervical lymph nodes: CT and MR criteria and differential diagnosis. AJR 1992; 158: 961-9.

10. Atula TS, Grenman R, Varpula MJ, Kurki TJ, Klemi PJ. Palpation, Ultrasound and Ultrasound - Guided Fine Needle Aspiration Cytology in the assessment of cervical lymph node status in Head and Neck cancer patients. Head and Neck 1996; 18:545-551.

11. Baatenburg de Jong AJ, Rongen RJ, Lameris JS, et al. Metastatic neck disease. Palpation vs ultrasound examination, Arch Otolaryngol Head Neck Surg.1989, vol. 115, pp. 689-690.

12. Giovagnorio F, Caiazzo R, Avitto A. Evaluation of vascular patterns of cervical lymph nodes with power Doppler sonography. J Clin Ultrasound, 1997; vol. 25, pp.71-76.

13. Hajek PC, Salomonowitz E, Turk R, Tscholakoff D, Kumpan W, Czembirek H. Lymph nodes of the neck: evaluation with US, Radiology.1986; vol. 158, pp.739-742.

14. Ahuja AT, Ying M, Ho SSY \&Metreweli, C. Distribution of intranodal vessels in differentiating benign from metastatic neck nodes, ClinRadiol,2001; vol. 56, pp. 197-201.

15. Sato N, Kawabe R, Fujita K \&Omura S. Differential diagnosis of cervical lymphadenopathy with intranodal color Doppler flow signals in patients with oral squamous cell carcinoma. Oral Surg Oral Med Oral Pathol Oral Radiol Endod.1998; 86 : 482-488.

16. Ahuja A, Ying, M King, W \&Metreweli, C. A practical approach to ultrasound of cervical lymph nodes.J Laryngol Otol.1997; vol. 111, pp. 245-256.

17. Brekel MW, Stel HV, Castelijns, JA, et al. Cervical lymph node metastasis: assessment of radiologic criteria, Radiology. 1990; vol. 177, pp. 379-384.

18. Vassallo P, Wernecke K, Roos N \& Peters, PE. Differentiation of benign from malignant superficial lymphadenopathy: the role of high resolution US, Radiology. 1992; vol.183, pp. 215-220.

19. Tohnosu N, Onoda S \&Isono K. Ultrasonographic evaluation of cervical lymph node metastases in esophageal cancer with special reference to the relationship between the short to long axis ratio (S/L) and the cancercontent, JClin Ultrasound. 1989; vol.17, pp. 101-106.

20. Brnic, Z \&Hebrang. A Usefulness of Doppler waveform analysis in differential diagnosis of cervical lymphdenopathy, Eur Radiology,2003; vol. 13, pp. 175-180. 
21. Na DG, Lim HK, Byun HS et al. Differential diagnosis of cervical lymphadenopathy: usefulness of color Doppler sonography. AJR Am J Roentgenol. 1997; 168:1311-1316.

22. Steinkamp HJ, Mueffelmann M, Bock JC, et al. Differential diagnosis of lymph node lesions: a semiquantitative approach with colour Doppler ultrasound. $\mathrm{Br} \mathrm{J}$ Radiol. 1998;71:828-833.

23.Wu CH, Chang YL, Hsu WC, et al. Usefulness of Doppler spectral analysis and power Doppler sonography in the differentiation of cervical lymphadenopathies. AJR Am J Roentgenol. 1998;171:503-509.

24. Jeffrey RB, \& Ralls, PW. Color and power Doppler sonography.A teaching file. In Principles, pitfalls, and practical hints, Philadelphia: Lippincott Raven,1998; vol.18.

25. Rubin, JM, Bude, RO, Carson, PL, et al. Power Doppler US: a potentially useful alternative to mean frequen- cybased color Doppler US, Radiology.1994, vol.190, pp. 853-856.

26. Ahuja A, \& Ying M. Sonography of Neck Lymph nodes, Part II: Abnormal Lymph Nodes, Invest Radiol 2003,vol. 58, pp. 359-366.

27. Ahuja AT, Ying M, Yuen YH, Metrewali C. Power Doppler sonography of metastatic nodes from papillary carcinoma of the thyroid. ClinRadiol 2001; 56:284-288.

28. Solbiati L, Rizzatto G, Charboneau W. Lymph Nodes. In: Bruneton JN, Rubatelli L, Solbiati L. Ultrasound of Superficial structures. London: Churchill Livingstone, 1995; 281-301.

29. Dangore SB, Degwekar SS \&Bhowate RR. Evaluation of the efficacy of colour Doppler ultrasound in diagnosis of cervical lymphadenopathy.Dentomaxillofacial Radiology. 2008; 37: 205-212.

30. Ahuja A, Ying M. An overview of neck node sonography. Invest Radiol. 2002; 37: 333-342.

31. Dragoni F, Cartoni C, Pescarmona E, Chiarotti F, Puopolo M, Orsi E et al. The role of High Resolution Pulsed and Color Doppler Ultrasound in the Differential Diagnosis of Benign and Malignant Lymphadenopathy.Cancer.1999; 85: $2485-2490$.

32. Nakamura T, Sumi M. Nodal imaging in the neck: recent advances in US, CT and MR imaging of metastatic nodes. EurRadiol 2007; 17:1235-1241.

33. Steinkamp HJ, Maurer J, Cornehl M, Knobber D, Hettwer H \& Felix R. Recurrent cervical lymphadenopathy: differential diagnosis with color-duplex sonography, Eur
Arch Otorhinolaryngol.1994, vol.251, pp. 404-409.

34. Chang D-B, Yuan A, Yu, C-J, Luh, K-T, Kuo S-H \& Yang $P-C . D i f f e r e n t i a t i o n$ of benign and malignant cervical lymph nodes with color Doppler sonography, AJR Am J Roentgenol, 1994: vol. 162, pp. 965-968.

35. Sadat SMA, Rita SN, Zaman AU, Rab A, Husain MM, Ahmed M. High Resolution Sonography in Diagnosis of Metastatic Cervical Lymph Nodes in Oral Squamous Cell Carcinoma, Journal of Bangladesh College of Physicians and Surgeons,2010; Vol. 28, pp. 92-99. 